\title{
ON A GENERAL THEORY OF ADAPTATION AND SELECTION.
}

\author{
BY \\ HENRY EDWARD CRAMPTON, PH.D.
}

It is the purpose of the present brief article to state in general and non-mathematical form some of the results of statistical and experimental studies, dealing with lepidoptera, that have been in progress for nearly six years, and in the second place to develop on the foundation of these results a generalized conception of natural selection and its actual basis during the segregation of the fit or adapted and the unfit or unadapted individuals of a species. I am led to offer this statement in this form and at this time because many months must elapse before the statistical results of recent studies may be put in final form for publication, though the more general conclusions to be drawn from them may be stated in simple terms; and it is my desire, furthermore, to present the theory so that it may bear the scrutiny of the numerous investigators now at work upon the problems of variation and selection, in order that its validity may be tested in connection with different kinds of biological material. In a word, this paper is an outline of a fuller discussion that must be deferred until the complete statistical results of my own investigations may be brought into relation with those of other investigators of the problem of natural selection and of its actual basis.

I.

In I 899 a brief preliminary investigation was begun upon the pupæ of a saturnid moth, Philosamia cynthia, in order to ascertain whether there was a definite relation between the variability of various pupal structures and the elimination that took place after the larvæ spun their cocoons in the fall of the year and pupated. The same question was also examined with reference to the reduction in numbers that occurred when the pupx emerged in 
the following spring, when many individuals proved to be unable to form perfect moths, and thus offered a comparison with the pupæ that metamorphosed successfully and perfectly. The material possessed a peculiar interest for the reason that the pupa does not "use" many of its structures at all during its long period of quiescence but remains practically inactive until the time for emergence approaches. To state the results of this investigation in briefest form, it was found in many instances that the pupx which died before metamorphosis were of somewhat different types and were more variable than the surviving individuals; and the same relation between elimination at the time of metamorphosis and structural variation appeared on the basis of a statistical examination of the two groups of pupæ distinguished at that time. ${ }^{1}$

Since 1900, the same species has been much more extensively examined to see if similar phenomena were exhibited in other years, and other forms of related moths have also been investigated-i.e., cecropia, promethea, ruber, jorulla, etc. The results have been confirmatory, in that in every series where successful pupæ have been compared with unsuccessful pupæ some of the characters exhibit the stated relation between variation and elimination.

Nevertheless, the conclusion that this relation was a general and a final one did not appear to me to be justified, for there were many cases where the reverse was true, where, that is, the survivors were of the same type as the others but were more variable, or they were of the same type and variability. In addition, the characters that exhibited "selection," where it was indicated, were of such a nature that they could hardly have served the pupa either advantageously or disadvantageously. The pupa does not "use" its antenna, and yet the pupæ that succeeded in producing perfect moths often possessed antennæ that were certainly selectively different from those of the contrasted unsuccessful group. It was inferred, therefore, that selection was "indirect," and that the real basis for selection was not to be sought in the series of individual characters themselves but in the condition of correlation between and among these characters. The conclusion of the preliminary study reads as follows:

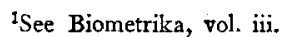


". . . the test of fitness or unfitness has reference to the physiological and morphological co-ordination or correlation among the constituents of the whole organism, and . . . any relaxation in either series, in a formative sense or otherwise, results in an instability which may culminate in death, and which expresses itself in structural deviation as well as in a higher degree of variability."

It is implied in the foregoing that a distinction may be made between formative correlation and functional correlation. In a later instalment ${ }^{1}$ the subject is discussed at length, and it is contended that the condition of correlation exhibited by the structures of the pupa is dependent upon the correlation of the formative factors or agencies which control the manufacture of the pupa by the larva, while the immediate functional elements are concerned scarcely if at all. The case is therefore quite different from that of the moth, where indeed formative factors of the general condition of correlation must be operative, but where the physiological co-ordination of the imaginal structures has a large share in determining the "fitness" of the organism. But entirely aside from the relative values to be assigned to these two classes of factors, the point is that the separate "characters" do not serve directly as adaptive or unadaptive elements of the organism, but they do so only in so far as they exist in close or loose correlation with other structural and functional characteristics.

\section{II.}

The truth of the conclusion stated was next put to the test of quantitative determination. The co-efficients of correlation were determined, according to the familiar methods, in the case of the characters that had been previously treated individually in their relation to elimination, and the co-efficients of correlation of the two groups were compared, with positive results. While it is true that the general condition of correlation, regarded as the basis for elimination, is only imperfectly indicated by the degree of correlation between any two characters and that the co-efficients of multiple correlation involving three or more characters would be more reliable as indices of this condition, yet if the principle be true

\footnotetext{
${ }^{1}$ Now in press, Biometrika.
} 
the advantage in favor of the surviving or more successful group of pupæ should appear more clearly where the co-efficients of correlation are used than where the comparison with the eliminated group is based upon the types and variabilities of the individual characters concerned. Such is, indeed, the case. While the former group is not invariably the superior in correlation, there is a smaller proportion of negative cases than where the individual characters are taken singly; so that definite confirmation is found for the conclusion reached at first entirely by inference.

\section{III.}

It now becomes the task to develop the principle of "the correlative basis for selection" so as to cover the wider range, over which, I believe, it extends. And I may state at the outset that statistical results have already been obtained proving in part that the wider range is indeed covered, though in the nature of the case, as will appear, complete mathematical demonstration is impossible.

So far, the general condition of correlation, which it is contended serves as the basis for elimination, has been regarded as determined by the whole series of internal or organismal characters taken together. We may next attempt to bring the series of environmental conditions or influences into the case by taking as an illustration the correlation between a single internal character as representing the whole series of internal characters and a single external character as a representative of that series. The first is "length of pupal period" in days, and the second is the "time of the year." Neither of these varieties is simple, it is true. The time of emergence will depend upon a number of things, upon the time of pupation, upon the weight of the whole organism, which, it is found, is indeed correlated with the type character; while in the second place the time of emergence is dependent also upon the time of the year, as increase of temperature hastens metamorphosis. But the point is rather, that when a given series of pupæ is kept under natural conditions of temperature, their times of emergence, even when they are members of a single family, will form a curve of error, like that of structural character such as antenna length, weight, etc. Likewise, the time of the year reckoned as so many days from an arbitrary date such as January first, will form a 
curve; and this external "character" too, is compound or at least representative of a series of external influences that affect lepidoptera, for not only will temperature conditions agree with calendar time, but food-supply and many other things will follow in a general way the temporal curve. It is clear, I think, that a certain degree of correlation between time of the year and metamorphosis will be adaptive, while a low degree will be unadaptive. Those individuals that mature too early will, even if they find mates, produce eggs and larvæ that will find poor food-supply, while those that emerge too late, supposing that they too find similar mates, will produce larva that will not have time to become full fed before cold weather will kill them and cut off their food-supply. Facts might be cited, showing still further that those that differ most from the average as regards the time of metamorphosis, vary also in unadaptive directions in internal characters, producing few eggs, possessing imperfect wings, and in other ways. It is needless to amplify the disadvantages that a lack of correlation with external influences or conditions would entail.

In brief, then, we find that the principle of correlative basis for selection involves not only the whole constitution of the organism itself, but the whole series of graded external influences as well, be these inorganic or organic, homogeneric or heterogeneric.

\section{IV.}

A few words are necessary with regard to the relations of the conception presented above. In the first place, it differs from the general theories hitherto brought forward in having a concrete basis in the results of statistical investigations of correlation and variation, and secondly, in that it places the series of external conditions on the same plane as the series of internal conditions, in their relation to the final welfare of the organism, regarding them also as varying according to the familiar laws of error. How far it may be justifiable to extend this principle over the external world, remains for future investigation; but it will be possible, as I belive, to utilize statistical methods in such investigations.

Selection is not regarded as in any way originative but only as judicial, so to speak. As the members of any species present themselves at the bar, "selection" decides the question of survival 
or destruction on the basis of the condition of correlation that is exhibited. Adaptation receives a precise definition: it means a degree of correlation, capable of numerical determination; and the question as to the utility of any given character becomes subordinate to the question of the effectiveness of any given combination of unit-characters, working in a functional of formative complex.

Finally, to possess an evolutionary value, this conception must be taken in connection with the view that the heritable characters of an organism are congenitally determined. The heritable nature of fluctuations as contrasted with mutations, however, is not a matter that is necessarily brought into court.

Barnard College, Columbia University, June 10, 1905 . 